\title{
In-vivo Convex Array Vector Flow Imaging
}

\author{
Jensen, Jørgen Arendt; Brandt, Andreas Hjelm; Nielsen, Michael Bachmann
}

\section{Published in:}

Proceedings of IEEE International Ultrasonics Symposium

Link to article, DOI:

10.1109/ULTSYM.2014.0082

Publication date:

2014

Document Version

Early version, also known as pre-print

Link back to DTU Orbit

Citation (APA):

Jensen, J. A., Brandt, A. H., \& Nielsen, M. B. (2014). In-vivo Convex Array Vector Flow Imaging. In Proceedings of IEEE International Ultrasonics Symposium (pp. 333-336). IEEE. https://doi.org/10.1109/ULTSYM.2014.0082

\section{General rights}

Copyright and moral rights for the publications made accessible in the public portal are retained by the authors and/or other copyright owners and it is a condition of accessing publications that users recognise and abide by the legal requirements associated with these rights.

- Users may download and print one copy of any publication from the public portal for the purpose of private study or research.

- You may not further distribute the material or use it for any profit-making activity or commercial gain

- You may freely distribute the URL identifying the publication in the public portal

If you believe that this document breaches copyright please contact us providing details, and we will remove access to the work immediately and investigate your claim 
Paper presented at the IEEE International Ultrasonics Symposium, Chicago, Il., USA, 2014:

\section{In-vivo Convex Array Vector Flow Imaging}

Jørgen Arendt Jensen ${ }^{1}$, Andreas Hjelm Brandt ${ }^{1,2}$ and Michael Bachmann Nielsen ${ }^{2}$

${ }^{1}$ Center for Fast Ultrasound Imaging, Biomedical Engineering group, Department of Electrical Engineering, Bldg. 349, Technical University of Denmark, DK-2800 Kgs. Lyngby, Denmark

${ }^{2}$ Department of Radiology, Rigshospitalet, Copenhagen University Hospital, Denmark

To be published in Proceedings of IEEE International Ultrasonics Symposium, Chicago, Il., USA, 2014. 


\title{
In-vivo Convex Array Vector Flow Imaging
}

\author{
Jørgen Arendt Jensen ${ }^{1}$, Andreas Hjelm Brandt ${ }^{1,2}$ and Michael Bachmann Nielsen ${ }^{2}$ \\ ${ }^{1}$ Center for Fast Ultrasound Imaging, Department of Electrical Engineering, \\ Technical University of Denmark, DK-2800 Lyngby, Denmark \\ ${ }^{2}$ Department of Radiology, Rigshospitalet, Copenhagen University Hospital, Denmark
}

\begin{abstract}
In-vivo VFI scans obtained from the abdomen of a human volunteer using a convex array transducers and transverse oscillation vector flow imaging (VFI) are presented. A 3 MHz BK Medical 8820e (Herlev, Denmark) 192-element convex array probe is used with the SARUS experimental ultrasound scanner. A sequence with a 129-line B-mode image is followed by a VFI sequence in 17 directions with 32 emissions in each direction. The pulse repetition frequency was set to $5 \mathrm{kHz}$, and the intensity and MI were measured with the Acoustic Intensity Measurement System AIMS III (Onda, Sunnyvale, California, USA). The derated $I_{s p t a .3}$ was $79.7 \mathrm{~mW} / \mathrm{m}^{2}$ and MI was 1.32 , which are within FDA limits for abdominal scans. The right liver lobe of a 28-year healthy volunteer was scanned with a view of the main portal vein and vena cava inferior at a frame rate of 7.4 Hz. Thirty frames were acquired, giving 4 seconds of data. For this volunteer the duration corresponded to roughly 3 heartbeats. The velocities were found at a beam-to-flow angle of $72 \pm 21^{\circ}$, where a conventional CFM scan would yield poor results. Three VF images from the same position in the cardiac cycle were investigated and the mean lateral velocities were $-0.079,-0.081$ and $-0.080 \mathrm{~m} / \mathrm{s}$ showing the consistence of the in-vivo results.
\end{abstract}

\section{INTRODUCTION}

Transverse oscillation vector flow imaging (VFI) can be used for visualizing the complex flow in the human circulation without angle compensation. Currently it is restricted to peripheral vessels due to the employment of linear array probes. The field of view in VFI can be increased by using convex array transducers, and this paper presents the first in-vivo VFI scans obtained from the abdomen of human volunteers.

Vector velocity imaging has been developed and commercially introduced for linear array transducers using the transverse oscillation (TO) approach [1], [2], [3]. This can be used for studying the complex hemodynamics in e.g. the carotid artery, for dialysis patients, and in the heart. The setup is, however, limited to small parts scanning and vessels no deeper than $6 \mathrm{~cm}$, due to the limited aperture and often high frequency used in the linear arrays employed. The method has therefore been further developed for both phased array [4] and convex array scanning [5] to increase the penetration depth and also used in tissue motion estimation [6], [7]. Currently TO vector flow imaging for convex arrays has only been demonstrated for flow rig measurements [5]. The purpose of this paper is to show the first in-vivo examples of applying the method to human volunteers.

The design of the TO fields for the set-up is briefly described in Section II, and the measurement and processing are detailed in Section III. The intensities of the sequence have been
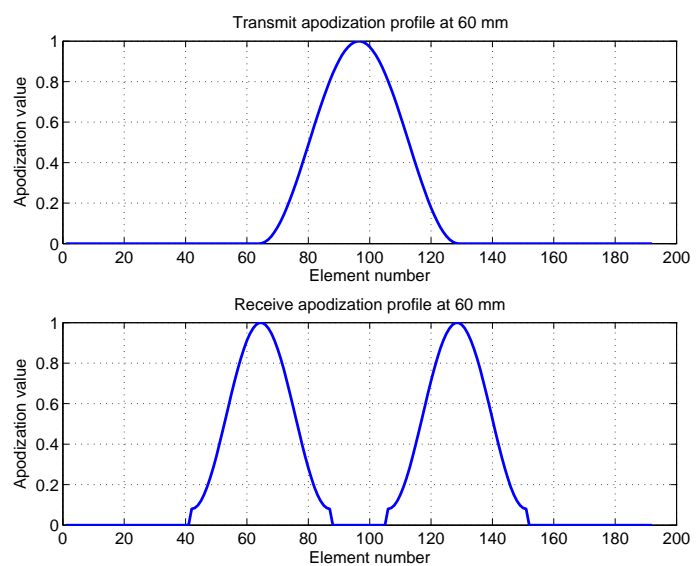

Fig. 1. The top graph shows the apodization employed during transmit, and the graph at the bottom shows a typical receive apodization function employed in TO imaging.

measured and are shown in Section IV. A number of in-vivo examples are shown in the results Section V.

\section{TO FIELDS}

The TO method relies on creating a controlled lateral oscillation by having a receive apodization function with two peaks as shown in Fig. 1. This ensures the generation of a transverse oscillation as there is a Fourier relation between the apodization function and the ultrasound $\mathrm{CW}$ field at the focus or in the far-field [1], [8]. The TO wavelength is

$$
\lambda_{x}=\frac{2 \lambda D}{P_{d}}=\frac{2 \lambda D}{N_{d} P_{i}},
$$

where $\lambda$ is the normal axial wavelength, $D$ is the depth, and $P_{d}$ is the distance between the two peaks in the apodization function. The transducer pitch is $P_{i}$ and the number of elements between the peaks is $N_{d}$. Assuming that the lateral oscillation wavelength can be designed to be four times the pitch of the transducer $\left(\lambda_{x}=4 P_{i}\right)$, the number of elements between the peaks is:

$$
N_{d}=\frac{2 \lambda D}{P_{d}}=\frac{2 \lambda D}{4 P_{i}^{2}} .
$$

The width of the peaks in the apodization function can be found from

$$
N_{w}=\frac{\lambda D}{2 F_{\# T O} P_{i}},
$$

where $F_{\# T O}$ is the F-number in receive, 

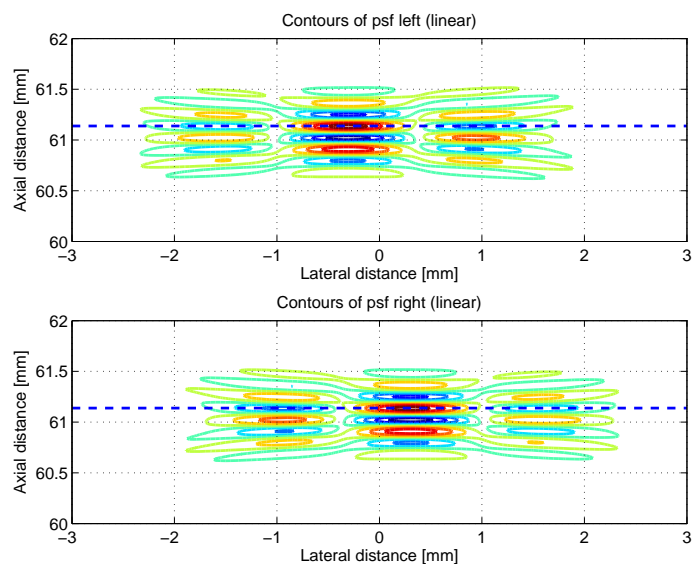

Fig. 2. Linear contour plots of the left (top) and right (bottom) point spread functions at a depth of $60 \mathrm{~mm}$.
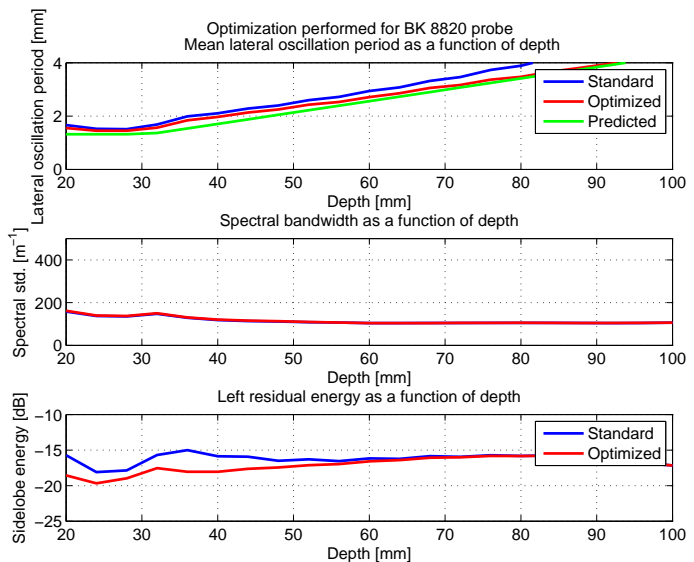

Fig. 3. The top graph shows the obtained lateral wavelength before (blue curve) and after optimization (red curve). The green curve is $\lambda_{x}$ predicted from (1). The middle graph shows the spectral bandwidth, and the lower graph shows the amount of residual energy for negative frequencies when making a Fourier transform of the complex point spread function.

These equations give the initial design criteria for the apodization function, and an estimate lateral oscillation wavelength can then be found by (1) for a continuous wave field. The wavelength will be slightly different for a pulsed field and away from the transmit focus. Simulations and optimizations as described in [5] are therefore employed for getting the best possible setup. The optimized lateral field is shown in Fig. 2, where the top plots shows the left field and the bottom the right. Fig. 3 shows the obtained lateral wavelength before (blue curve) and after optimization (red curve) on the top graph. The green curve is $\lambda_{x}$ predicted from (1). The middle graph shows the spectral bandwidth, and the lower graph shows the amount of residual energy for negative frequencies when making a Fourier transform of the complex point spread function shown in Fig. 2. The optimization yields an improved point spread function and hereby reduces the bias of the results [5].

\section{MEASUREMENT SETUP AND PROCESSING}

A $3 \mathrm{MHz}$ BK Medical 8820e (Herlev, Denmark) 192element convex array probe is used with the SARUS scanner
[9]. A sequence with a 129-line B-mode image is followed by a VFI sequence in 17 directions with 32 emissions in each direction. The B-mode image is focused at a depth of $42 \mathrm{~mm}$ with an $\mathrm{F} \#$ of 2 and a Hanning apodization in transmit. The VFI emissions are focused at $105 \mathrm{~mm}$ with a F\# of 5 and use 64 transmit elements with Hanning apodization. Four elements are skipped between the center element for each VFI direction. All 192 channels were sampled at a frequency of $17.5 \mathrm{MHz}$. The receive apodization consisted of two 46 element wide peaks separated by 64 elements between peaks. This gave a TO wavelength of $2.71 \mathrm{~mm}$ at $60 \mathrm{~mm}$ in a Field II simulation that yielded a residual left side energy below $-16.6 \mathrm{~dB}$. The pulse repetition frequency was set to $5 \mathrm{kHz}$, yielding a frame rate of $7.4 \mathrm{~Hz}$. Thirty frames were acquired, giving 4 seconds of data, and for this volunteer the duration corresponded to roughly 3 heartbeats.

The data fill 15.1 Gbytes on disk and were stored in 32 minutes, giving a storage rate of $470 \mathrm{MBytes} / \mathrm{min}$ or 7.86 MBytes/s from the RAM in SARUS to the Linux storage cluster. The data were processed using the BFT3 toolbox [10] in Matlab, and the velocity vector was found using the estimator from [11]. Echo canceling was performed by averaging across all emissions and then subtracting this from the signals. A discriminator based on the energy before and after echo canceling was also used. Velocity estimates were shown when this energy after was $1.5 \%$ of the energy before echo canceling.

\section{INTENSITY MEASUREMENTS}

The intensity and MI were measured using the Acoustic Intensity Measurement System AIMS III (Onda, Sunnyvale, California, USA) with an Onda HGL-0400 hydrophone. It was connected to one receive channel in the SARUS system, which makes it possible to make a fast acquisition of the intensity for the whole sequence as described in [12]. The measurement was conducted at a $2 \mathrm{kHz}$ pulse repetition frequency, and the result are shown in Figs. 4 and 5. The peak derated MI in this sequence is 1.32 at $(x, y, z)=(8.0,0.0,40.0) \mathrm{mm}$, which is below the FDA limits of 1.90 [13].

The derated $I_{\text {spta.3 }}$ in this sequence is $31.87 \mathrm{~mW} / \mathrm{cm}^{2}$ at $(x, y, z)=(2.0,0.0,20.0) \mathrm{mm}$. The intensity is fairly evenly spread out over the imaging region and is highest fairly close to the transducer. The pulse repetition frequency $f_{p r f}$ can therefore be scaled by a factor 22.59 to $45.19 \mathrm{kHz}$ before reaching the FDA limit of $720 \mathrm{~mW} / \mathrm{cm}^{2}$. A pulse repetition frequency of $5 \mathrm{kHz}$ was used during the in-vivo measurements. This gives a derated $I_{\text {spta. }}$ of $79.7 \mathrm{~mW} / \mathrm{m}^{2}$ and an MI of 1.32 , which are both within FDA limits for abdominal scans.

\section{In-vivo RESULTS}

Scans were conducted on a fit 28-year volunteer at rest. Initially he was scanned with a commercial scanner to find the best possible view. Data were then acquired by the SARUS scanner using a real-time preview mode only showing the Bmode image and not the vector velocity image. Data were then 


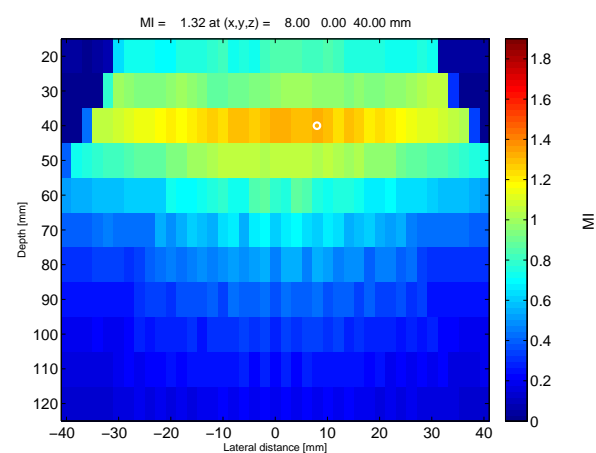

Fig. 4. Derated MI. The white circle indicates the position of the peak value.

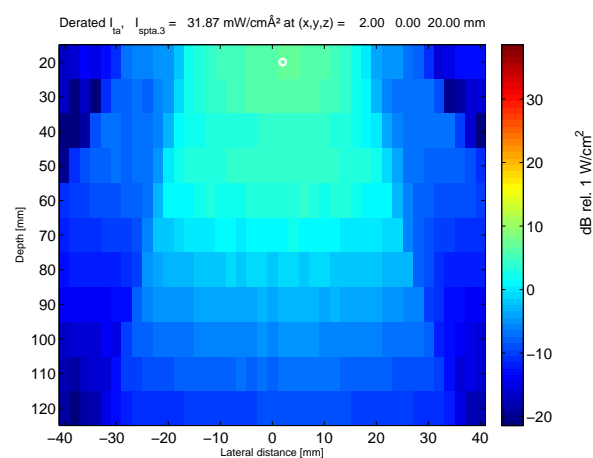

Fig. 5. Derated $I_{t a .3}$. The white circle indicates the position of $I_{s p t a .3}$.

stored and processed off-line in Matlab to yield the vector velocity images.

The right liver lobe of the volunteer was scanned with a view of the main portal vein and vena cava inferior, and the resulting images are shown in Fig. 7. In general it is difficult to validate results from in-vivo images. One approach is to look at consistency across a number of heart beats, which can be found from the velocity data. The axial velocity component at the center of the vessel is shown in Fig. 6 as a function of time to find images at the same phase in the cardiac cycle. The time between peaks is $1.35 \mathrm{~s}$ giving a heart rate of 44 beats $/ \mathrm{min}$. This corresponds to a cardiac cycle length of roughly 10 frames in this sequence and images have been selected for display based on the peak positions in the graph.

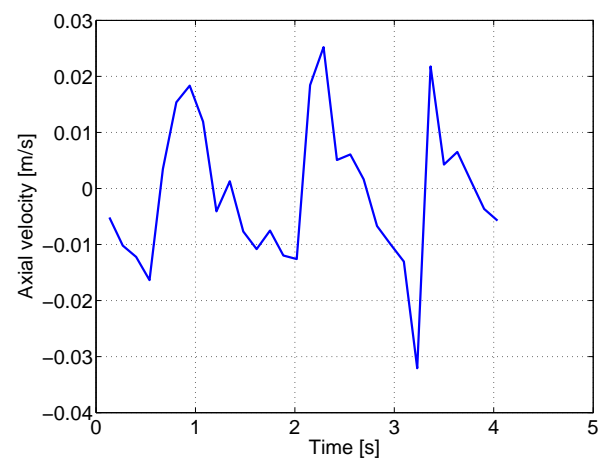

Fig. 6. Axial velocity component as a function of time at the center of the main portal vein.
TABLE I

MEAN VELOCITIES AND ANGLES ESTIMATED FROM THE VELOCITY IMAGES.

\begin{tabular}{c|c|c|c} 
Frame & $\begin{array}{c}\text { Mean angle } \\
\text { deg. }\end{array}$ & $\begin{array}{c}\text { Angle std } \\
\text { deg. }\end{array}$ & $\begin{array}{c}\text { Mean velocity } \\
\mathrm{m} / \mathrm{s}\end{array}$ \\
\hline & & & \\
6 & 70 & 23 & -0.079 \\
16 & 73 & 21 & -0.081 \\
25 & 74 & 22 & -0.080 \\
\hline
\end{tabular}

The resulting vector velocity images are shown in Fig. 7 for the three heart beats, when assuming a heart rate of 44 beats/minute. The flow progresses from left to right in the image, and a fairly uniform velocity profile is seen at positive lateral distances in all three images. The velocity arrows roughly follow the boundaries of the vessel. At lateral distances between 0 and $-10 \mathrm{~mm}$, a more disturbed flow is seen with two velocity peaks. The B-mode image also has a larger brightness indicating that the vessel might not be straight in this region. The vessel narrows at the inlet on the left, and the velocity, thus, increases, which is indicated by the longer arrows.

Table I shows the estimated mean angle and mean lateral velocities for the three images. The angle is close to $72^{\circ}$, which is fairly close to a transverse flow and, thus, not usable in a conventional scan set-up. The angle spread is around $22^{\circ}$ and, thus, encompasses a fully transverse flow. The depth is fairly high compared to the transducer size and angulation will therefore be difficult in a conventional CFM or spectral measurement. The mean lateral velocity is around $-0.08 \mathrm{~m} / \mathrm{s}$ for all frames and indicates the consistency of the in-vivo data across the heart cycles.

A second in-vivo example is shown in Fig. 8 for the same volunteer. Here liver veins are shown. In this image the velocity vectors mostly follow the vessel wall and a connecting vein can be seen at the bottom to the left of the main vein. Arrows pointing into the main vein along its upper wall also indicate connecting veins. The example spans a larger range of depths, and more uncertain estimates are obtained during the cardiac cycle as the signal-to-noise ratio is lower and the TO method is optimized for imaging at $60 \mathrm{~mm}$. The estimation is, thus, worse at other depths as the lateral wavelength deviates from the true as shown in Fig. 3. Dynamic focusing should therefore ideally be used in this case.

\section{CONCLUSION}

Vector flow imaging using a convex array and transverse oscillation has been developed and used in-vivo on the main portal vein for a healthy 28 -year old male volunteer. Three cardiac cycles were acquired, and the vector flow images were consistent in terms of mean lateral velocity and mean angle of the flow in the vessel. The method therefore expands on the capabilities of vector flow imaging making it possible to penetrate deeper into the body and still maintain angle independent results. This can significantly expand the clinical possibilities in e.g. the abdomen. 


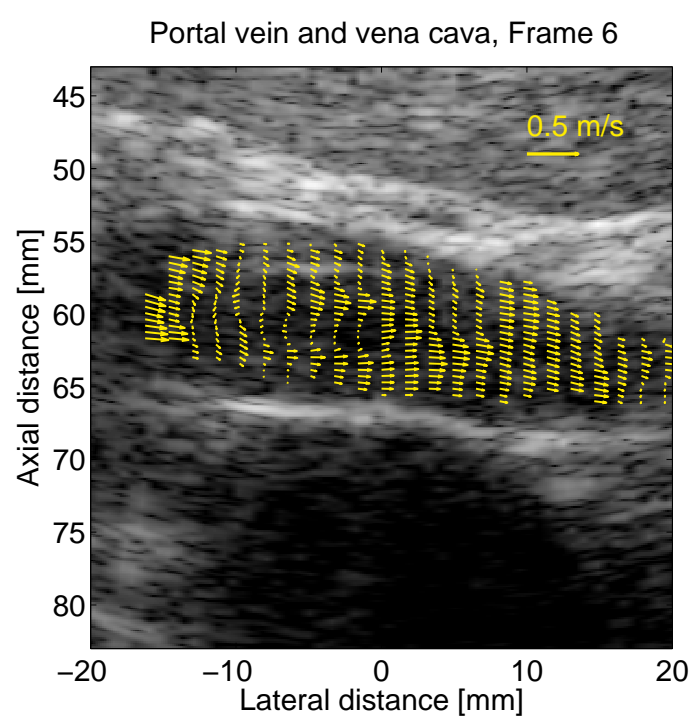

Portal vein and vena cava, Frame 16

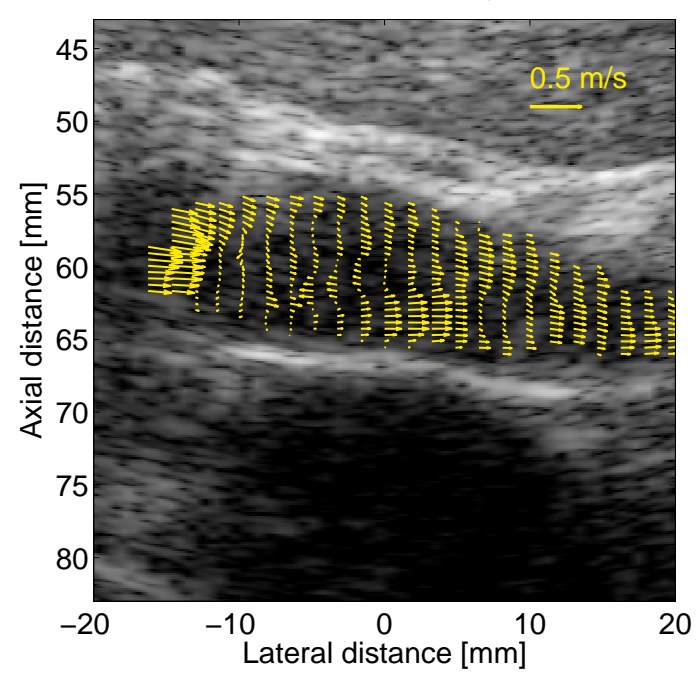

Portal vein and vena cava, Frame 25

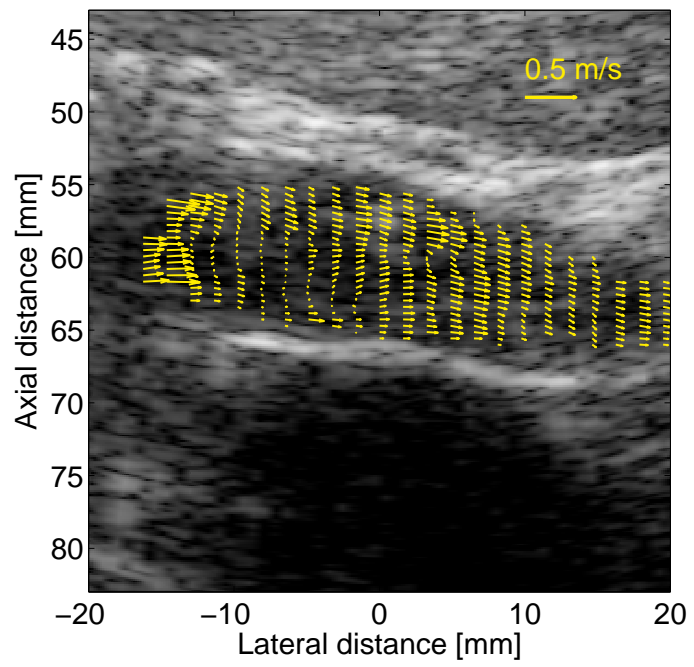

Fig. 7. in-vivo example of the main portal vein and vena cava inferior for a fit 28 years old male. Three frames are shown at the same instance in the cardiac cycle assuming a heart rate of 44 beats/minute.

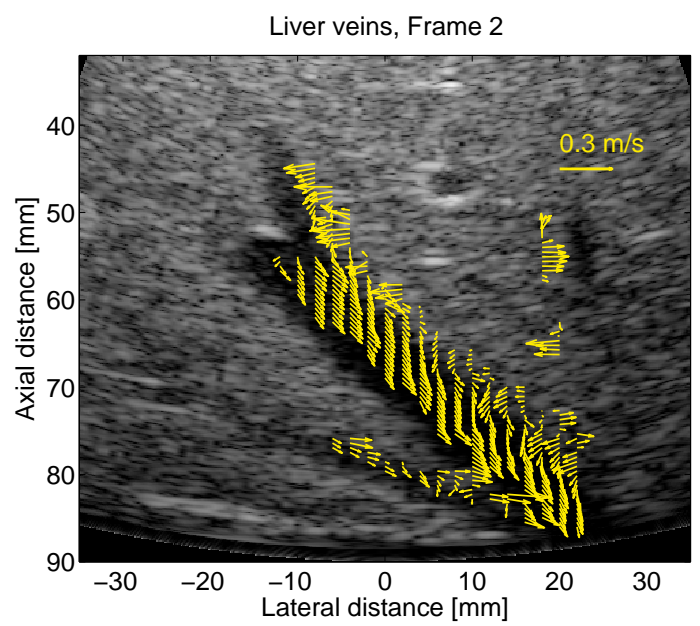

Fig. 8. in-vivo example of the liver veins for a fit 28 years old male.

\section{ACKNOWLEDGEMENT}

This work was supported by grant 82-2012-4 from the Danish Advanced Technology Foundation and by B-K Medical.

\section{REFERENCES}

[1] J. A. Jensen and P. Munk, "A New Method for Estimation of Velocity Vectors," IEEE Trans. Ultrason., Ferroelec., Freq. Contr., vol. 45, pp. 837-851, 1998.

[2] M. E. Anderson, "Multi-dimensional velocity estimation with ultrasound using spatial quadrature," IEEE Trans. Ultrason., Ferroelec., Freq. Contr., vol. 45, pp. 852-861, 1998.

[3] P. M. Hansen, M. M. Pedersen, K. L. Hansen, M. B. Nielsen, and J. A. Jensen, "Demonstration of a vector velocity technique," Ultraschall in Med., vol. 32, pp. 213-215, 2011.

[4] M. J. Pihl, J. Marcher, and J. A. Jensen, "Phased-array vector velocity estimation using transverse oscillations," IEEE Trans. Ultrason., Ferroelec., Freq. Contr., vol. 59, no. 12, pp. 2662-2675, 2012.

[5] J. A. Jensen, "Optimization of transverse oscillating fields for vector velocity estimation with convex arrays," in Proc. IEEE Ultrason. Symp., July 2013, pp. 1753-1756.

[6] C. Sumi, "Displacement vector measurement using instantaneous ultrasound signal phase - multidimensional autocorrelation and Doppler methods," IEEE Trans. Ultrason., Ferroelec., Freq. Contr., vol. 55, no. 1 , pp. 24-43, 2008.

[7] H. Liebgott, A. Basarab, P. Gueth, D. Friboulet, and P. Delachartre, "Transverse oscillations for tissue motion estimation," Ultrasonics, vol. 50, no. 6, pp. 548-555, 2010.

[8] J. W. Goodman, Introduction to Fourier optics, 2nd ed. New York: McGraw Hill Inc., 1996.

[9] J. A. Jensen, H. Holten-Lund, R. T. Nilsson, M. Hansen, U. D. Larsen, R. P. Domsten, B. G. Tomov, M. B. Stuart, S. I. Nikolov, M. J. Pihl, Y. Du, J. H. Rasmussen, and M. F. Rasmussen, "SARUS: A synthetic aperture real-time ultrasound system," IEEE Trans. Ultrason., Ferroelec., Freq. Contr., vol. 60, no. 9, pp. 1838-1852, 2013.

[10] J. M. Hansen, M. C. Hemmsen, and J. A. Jensen, "An object-oriented multi-threaded software beamformation toolbox," in Proc. SPIE Med. Imag., vol. 7968, March 2011, pp. $79680 Y$ 1-9. [Online]. Available: http://dx.doi.org/10.1117/12.878178

[11] J. A. Jensen, "A New Estimator for Vector Velocity Estimation," IEEE Trans. Ultrason., Ferroelec., Freq. Contr., vol. 48, no. 4, pp. 886-894, 2001.

[12] J. A. Jensen, M. F. Rasmussen, M. B. Stuart, and B. G. Tomov, "Rapid measurements of intensities for safety assessment of advanced imaging sequences," in Proc. SPIE Med. Imag., 2014, p. In Press.

[13] FDA, "Information for manufacturers seeking marketing clearance of diagnostic ultrasound systems and transducers," Center for Devices and Radiological Health, United States Food and Drug Administration, Tech. Rep., 2008. 